\title{
The MDGs in Historical Perspective
}

\author{
Richard Jolly
}

Abstract Some 50 goals have been set over the UN's life, from goals for education in 1960 to the MDGs agreed at the Millennium Summit in New York in 2000. Cynics have charged that UN goals have been proposed and agreed with little thought, and rarely achieved. Based on research conducted for the UN Intellectual History Project, this short article argues that in fact, there has always been widespread discussion before approving goals and more progress in implementing them than is commonly recognised. And although the record of achievement is mixed and far from perfect, most of the goals have had considerable influence and many have been considerably achieved by a considerable number of countries.

\section{Introduction}

Some 50 goals have been set over the UN's life, from goals for education in 1960 to the Millennium Development Goals (MDGs) agreed at the Millennium Summit in New York in 2000. ${ }^{1}$ Goals have covered economic growth, life expectancy, child and maternal mortality, health and disease reduction, education and literacy, water, sanitation and hygiene, hunger and malnutrition, moves to sustainable development and support for all these efforts through increases in aid and development assistance. Cynics have charged that UN goals have been proposed and agreed with little thought - and rarely achieved. The facts are otherwise. Every goal has been subject to considerable debate before approval - often over lengthy periods and with opposition from various governments, mainly donor governments. And although the record of achievement is mixed and far from perfect, most of the goals have had considerable influence and considerable progress has been achieved in relation to the goals in a considerable number of countries.

\section{A brief history of UN goals}

The first goals were those for education, arising from three regional conferences organised by UNESCO around 1960. Goals emerging from the conferences covered the expansion of primary education over the two decades until 1980 and also the expansion of secondary and tertiary levels, mostly with regional differences. Coming at the beginning of independence for many countries, the goals had great political relevance in countries conscious of how education in their countries had been held back in the colonial era.

Soon after, the General Assembly set goals for economic growth over the 1960 s, as part of what was declared to be the Development Decade. Economic growth in developing countries was to be accelerated to reach a target rate of 5 per cent per annum by the end of the 1960s. Flows of public capital were to reach a level of 1 per cent of developed country GNP by 1970. Economic growth did indeed accelerate, with a rate of 5.5 per cent being achieved by all developing countries taken together and by some 50 individual countries. Total transfers to developing countries reached 0.79 per cent of the GNP of developed countries, with aid reaching 0.34 per cent. This led to a certain optimism for goal-setting for the Second Development Decade, when a target of 6 per cent growth per annum was set for the 1970s and the aid target focused solely on concessional transfers for which the famous 0.7 per cent target was set. Although the average rate of economic growth among developing countries was marginally higher in the 1970s, the target was missed. But never again were the decadal rates for developing countries as a whole so high.

In 1966, the UN's most dramatic and successful goal was set: for the eradication of smallpox within ten years. Smallpox had been a scourge of mankind for thousands of years and in 1966 was thought to be killing some 2 million people each 
year and was endemic in some 50 countries, including India, Pakistan, Bangladesh, Brazil and much of Africa. Many thought eradication impossible, including Marcelino Candau, then WHO Director-General. But with determined leadership from within the smallpox programme, remarkable progress was made, with the result that the final case of smallpox was tracked down in Somalia in 1977 - only 11 years after the goal had been set. ${ }^{2}$ The total cost of the programme was $\$ 100$ million from international sources and $\$ 200$ million from national ones - a total of $\$ 300$ million, the cost at the time of three fighter bombers. In contrast, the benefits of the campaign have been estimated at a minimum of $\$ 2$ billion per year in the avoidance of the need for vaccination and border controls, in addition to the avoidance of millions of deaths and much pock-marking illness.

None of the other goals has had such complete success - although the efforts towards the eradication of guinea worm and polio have made extraordinary progress. Actions towards the goals for the reduction of infant and child mortality have also been impressive - with only 13 countries now having infant mortality rates above 100 - a level reached by no developed country until the twentieth century.

Three goals have shown the least progress: the goals for the reduction of maternal mortality rates, for the accelerated reduction of illiteracy and for development assistance to reach the target of 0.7 per cent of GNP in each developed country. In each case, there are some good examples but not many. The goal for development assistance is especially shameful. Only five countries have reached it - and they are the ones which have built public support to enable them to consistently maintain their performance in relation to the goal: Denmark, the Netherlands, Norway, Sweden - all since the 1970s - and recently, Luxembourg. ${ }^{3}$ The EU have recently made commitments to the goal - Britain adopting it as their target for 2013 and France for 2015 .

The USA has never accepted the 0.7 per cent goal for development assistance. Until recently, when the MDGs were adopted as part of the
Millennium Declaration, the Bretton Woods Institutions never accepted UN goals as applying to their programmes or operations. In contrast, some parts of the UN have used goals as key objectives for their programmes, notably the WHO for the eradication of smallpox, and UNICEF in the 1980s and 1990s with goals for the reduction of child mortality, especially through the expansion in immunisation against measles, whooping cough, tetanus, diphtheria, polio, and TB, all killer diseases, especially for young children. UNICEF working with others showed how goals could be used for mobilising political commitment, popular awareness and local action for what it called a Child Survival and Development Revolution. In spite of the 1980s being a lost decade for economic development, with cutbacks in public expenditures and stagnation or declines in per capita income, in much of Latin American and Africa, immunisation rates rose from 10 to 15 per cent in 1980 to an average of 80 per cent of the child population in developing countries. Child deaths fell from 15 million to 12 million over the decade and have fallen further to under 9 million today.

\section{Conclusions}

These experiences show the value of goals: for mobilising political commitment and generating popular awareness around consensus development objectives, and as guidelines for coordinated action. The MDGs have achieved some of these. But so far, there has been an excessive simplicity in the way the MDGs have been promoted, running the risk of popular disillusion when it becomes clear that many of the goals will not be achieved in many countries by 2015 . This can be avoided if more attention is paid to other indicators of progress - for instance, to the rates of advance against the baseline situation in different countries, and with less focus on whether countries are or are not on track to meet the goals. More attention to comparative progress within each regional grouping would also help, identifying the more successful countries within each region against the less successful, thus generating a more realistic understanding of the challenges and progress as well as introducing a sense of interregional competition. 


\section{Notes}

1 This account draws on Jolly et al. (2009), especially Chapter 5 on Development Goals. A detailed review of each goal and an assessment of performance will be found in Chapter 10, pp. 257-67 of Jolly et al. (2004).

\section{References}

Henderson, D.A. (2009) Smallpox: The Death of a Disease, Amherst: Promethius Books

Jolly, Richard; Emmerij, Louis and Weiss, Thomas G. (2009) UN Ideas that Changed the World, Bloomington: Indiana University Press Jolly, Richard; Emmerij, Louis; Ghai, Dharam and Lapeyre, Frederic (2004) UN Contributions
2 Henderson (2009), who led the international effort, has written a fascinating and frank account.

3 Stokke (2009) provides a detailed account of the origins of development assistance and the 0.7 per cent goal.

to Development Thinking and Practice, Bloomington: Indiana University Press Stokke, Olav (2009) The UN and Development: From Aid to Cooperation, Bloomington: Indian University Press 